\title{
Application of Fuzzy Best Worse Multi Criteria Decision Making Method for Flood Prioritization
}

\section{Sarita Gajbhiye Meshram}

Ton Duc Thang University

Ali reza Ildoromi ( $\sim$ a.ildoromi@yahoo.com )

University of Malayer

Mehdi Sepehri

Yazd University

\section{Research Article}

Keywords: Flood, Prioritization, Best worse method, fuzzy

Posted Date: June 17th, 2021

DOI: https://doi.org/10.21203/rs.3.rs-581169/v1

License: (c) (i) This work is licensed under a Creative Commons Attribution 4.0 International License.

Read Full License 


\title{
Application of Fuzzy Best Worse Multi Criteria Decision Making Method for Flood Prioritization
}

\author{
Sarita Gajbhiye Meshram ${ }^{1,2}$, Ali Reza Ilderomi ${ }^{2 *}$, Mehdi Sepehri ${ }^{3}$ \\ ${ }^{1}$ Department for Management of Science and Technology Development, Ton Duc Thang \\ University, Ho Chi Minh City, Vietnam \\ ${ }^{2}$ Faculty of Environment and Labour Safety, Ton Duc Thang University, Ho Chi Minh City, \\ Vietnam \\ Email: gajbhiyesarita@gmail.com \\ $2^{*}$ Department of Watershed Management, Faculty of Natural Resources, Malayer University, \\ Hamadan, Iran, E-mail of corresponding author: Ildoromi@malayeru.ac.ir \\ ${ }^{3}$ Department of Watershed Management, Faculty of Natural Resources, Yazd University, \\ Yazd, Iran. E-mail:sepehri_mehdi@ymail.com;
}

ABSTRACT: Flood is one of the major problems of the sad ekbatan watershed, northern of Hamadan province, Iran. This problem imposes high damages to the economic issue. Therefore, prioritization of the study area based on the flooding degree can be considered for identifying hot spot flooded areas for performing soil and water conservation practices. In this study, in order to prioritize sub-watersheds of the case study from viewpoint of flooding degree, five flood-related criteria i.e. entropy of drainage network (En), index of connectivity (IC), stream power index (SPI), curvature (C) and curve number $(\mathrm{CN})$ were considered, then fuzzy based Best Worse Multi Criteria Decision Making (F-BWM) Method was used to assigning weights to used criteria and combination them to achieve flooding degree for each subwatershed. The results of prioritization of sub-watersheds indicated that the sub-watersheds 14 and 21 are most and least susceptibility areas to flooding correspondingly.

Keyword: Flood; Prioritization; Best worse method; fuzzy 


\section{Introduction}

Floods are one of the natural disasters that occur every year to global scale (Field et al., 2012). In recent decades, floods are known as the main defendants of financial and life losses. Despite these descriptions, there are some solutions that can be effective against reducing or preventing flood events (Adhikari et al.,2010; Smith and Ward, 1998). The results of studies conducted by the Forest, Rangeland and Watershed Management Organization (FRWMO) in Iran (19862007) show that 2498 flood events were occurred and resulted in the deaths of 3299 people, injuries of 1733 people, partial and complete destruction of 135092 and 1572 building units (totally 136,664 damaged and destroyed buildings) (Almasi and Soltani, 2017; Hajian et al., 2019; Hooshyaripor et al., 2020; Yadollahie, 2019).

Flood is one of the most frequent and costly hazard worldwide which impress approximately 20000 lives per year (Sarhadi et al., 2012).Until to data, it is incredible to prevent flood but some appropriate measures can be underpinned to somewhat compensate it (Termeh et al., 2018). In scale of catchment, given the inherent complexity of formulating flood risk management strategies and its high uncertainty due to some reasons such as large input data and long processing time, it is necessity to select sub-watershedsas a small-scale hydrological unit to prioritize them based on their flood potential (Aher et al., 2014; Anees et al., 2019; Shivhare et al., 2018). In this context, there are variety of approaches available to analysis and prioritize sub-watersheds using Multi Criteria Decision Analysis (MCDA) (Akay and Koçyiğit, 2020; Chitsaz and Banihabib, 2015; Ghaleno et al., 2020; Sepehri et al., 2019c),

Soil and Water Assessment Tool (SWAT)(Mishra et al., 2007; Talebi et al., 2019a), artificial neural network (ANN) (Dehghanian et al., 2020), Storm Water Management Model (SWMM)(Babaei et al., 2018), support vector machine (SVM) (Fan et al., 2018; Tehrany et al., 2014) and The Hydrologic Modeling System (HEC-HMS) (Malekinezhad et al., 2017; Talebi et al., 2019b). Among aforementioned methods, MCDA has been taking into account 
due to its capability to handle nonlinear and complex problems and its usability to prioritize ungauged watershed.

MCDA are most usable methods which can be used to manage large amount of data and solving decision making under scale, quantitative, qualitative and conflict factors (Fernández and Lutz, 2010; Mahmoud and Gan, 2018). The Analytic Hierarchy Process (AHP) which was developed by Saaty (1980), due to some reasons such as cost-effective, ease to used and understand has made to one of the most popular method among MCDA (Zou et al., 2013), which has been successful in various natural hazard studies such as landslide (Bahrami et al., 2020; Kayastha et al., 2013; Myronidis et al., 2016), flood magnitude (Lin et al., 2020; Sepehri et al., 2017; Swain et al., 2020), groundwater vulnerability(Abdullah et al., 2018; Das and Pal, 2020; Sener and Davraz, 2013).

Rahmati et al. (2016) identified most susceptibility sub-watersheds to flood magnitude using AHP and natural and anthropogenic factors. Mahmoud and Gan (2018) attempted to prepare flood hazard mapping in arid regions of Middle East using AHP and 10 flood- related factors i.e. annual rainfall, flow accumulation, distance to drainage network, elevation, slope, geology, land use/cover, drainage density, soil type and runoff. In other similar study, Dash and Sar (2020) used AHP to delineate flood susceptibility mapping. AHP was used to assigning weights to flood-related factors based on importance role of them on flood magnitude. The AHP and other similar methods is categorized as subjective or experts' knowledge-based methods (Sepehri et al., 2019b; Smithson, 1989). In these methods, for assigning weights to factors, it is necessity to compare factors relative to each other. The process of comparison is the main source of inconsistency of these methods (Guo and Zhao, 2017). In this regard, several methods were developed to reduce the number of pairwise comparisons. In recent years, a new method was introduced by Rezaei (2015). This method is more optimal version of AHP with the need of less compared data, causing more consistency of the results. However, the weak 
point of the BWM is related to kind of import data. This method such as AHP, use a limited 9point table. In here, experts face to a dilemma to choice a point of initial weighting to factors causing inconsistency in the results. Therefore, it is better to use fuzzy number other than limited 9-point table which is more in line with actual situations and can obtain more convincing ranking results (Ali and Rashid, 2019; Guo and Zhao, 2017).The sad ekbatan watershed in the field if floods and its related financial and ecological losses can be regarded as one of the most critical areas in central of Iran. However, there is no done comprehensive and efficient works to reduce the flood consequences. Thus the main objective of this study is to flood prioritization based on fuzzy- best worse multi criteria decision making method of efficient prioritizing sub-watersheds.

\section{Case study}

The sad ekbatan with an area of $180 \mathrm{~km}^{2}$ is watershed located in northern part of Hamadan province, Iran. The watershed coordinates system lies between $31^{\circ} 24 / 45^{\prime \prime}$ to $31^{\circ} 27 / 29^{\prime \prime}$ north; $41^{\circ} 55 / 20^{\prime \prime}$ to $41^{\circ} 57 / 34^{\prime \prime}$ east (Fig. 1). The elevation map ranges of 1948 to 3442 meters above the sea level. Based on sad ekbatan climatology data, the average annual rainfall and temperature is $343.11 \mathrm{~mm}$ and $+10.75{ }^{0} \mathrm{C}$. From viewpoint of geology, the case study has located in Sanandaj- Sirjan metamorphic zone which has been categorized with sedimentary rock units, including S1 ‘Mb ‘Schg ‘Schan ‘Schst ‘hc ‘Schsp ‘K1s,c ‘Qt. Rangeland is one the most important covers in the case study, but in two last decade due to economic and social problems, this cover has been transferred to farming areas, leading to an increase of $30 \%$ in rate of runoff volume (Farokhzadeh et al., 2015).

Fig.1: location map of the case study

1




\section{Materials and Methods}

The used procedural in this study, is based on studies ofHazarika et al. (2018);Sepehri et al. (2019a); Arabameri et al. (2019) and Costache and Bui (2020)which can be summarized as three main stages:

1. Establishing flood-related indices.

2. Appling ensemble of Fuzzy method and BWM to assigning weights to used indices based on importance of them on flood magnitude.

3. Prioritization of sub-watersheds using weighted overlay method (WOM) (Fig.2).

\section{Fig.2: Flowchart of the used methodology}

\subsection{Flood-related indices}

The flood magnitude is a function of metrological and catchment properties which known as flood-related indices(Chen et al., 2019; Fernández and Lutz, 2010; Hong et al., 2018). Therefore, an acceptable flood hazard mapping is depending on quality of the spatial and temporal the indices. In this study based on best of our knowledge and field surveys, five floodrelated indices were considered. Those factors are: entropy of drainage network (En), index of connectivity (IC), stream power index (SPI), curvature (C) and curve number $(\mathrm{CN})$.

Entropy of drainage network (En): One of the most important geomorphic indices that can play a very important role in flood frequency and probability is the complexity of the drainage network(Ariza-Villaverde et al., 2013; Veltri et al., 1996; Zhang et al., 2015). In most studies of flood subjects, the authors use the simple features of drainage network for description of it. These features such as length of drainage network, radius of drainage network curvature, drainage density have not an accurate description of drainage network(Ildoromi et al., 2019; Zhang et al., 2015). In recent years, a new concept as irregularity has been raised between scholars to better describe the drainage network. The entropy concept, is one of the most 
popular methods which can be used to assess the irregularity features of drainage network. To calculate entropy of drainage network, it is necessity to use box-counting algorithm. In the algorithm, the drainage network is beaks down to various pixel sizes and then by using Eq. 1,

132 the entropy of drainage network is calculated.

$$
P_{i}=-k \sum_{j=1}^{n} f_{i j} \ln f_{i j}
$$

133

Where

$$
\begin{gathered}
f_{i j}=\frac{r_{i j}}{\sum_{j=1}^{n} r_{i j}} \\
r_{i j}=\frac{x_{i j}-\min \left\{x_{i j}\right\}}{\max \left\{x_{i j}\right\}-\min \left\{x_{i j}\right\}}
\end{gathered}
$$

Index of connectivity (IC): In hydrology studies, the concept of connectivity is used for description of geomorphic features (Wohl et al., 2019) and process-based dynamic researches and can be defined as degree of sediment or runoff coupling between landscape elements (Borselli et al., 2008; Heckmann et al., 2018). Sediment connectivity showing the potential moving of a special particle of source to sink to different temporal and spatial scales (Fryirs, 2013; Llena et al., 2019). In order to prepare a flood hazard map with high accuracy, it is necessity to use connectivity indices.

In recent years, several hydrological connectivity indices have been developed to evaluate the potential for a landscape to be connected (Calsamiglia et al., 2018). On the other hand, the existence of the raster-based indices can be considered as an opportunity to assess the spatial distribution of the sediment connectivity (Llena et al., 2019). The index of connectivity which introduced by Borselli et al. (2008)is known as most popular method which has used in this study (Eq. 2).

$$
I C=\log _{10}\left(\frac{D u p}{D d n}\right)
$$


152 The numerator of this equation (i.e. Dup) which called as upslope component, demonstrates the potential of upslope of a pixel in downward routing of sediment/runoff and denominator (i.e. Ddn) represents the flow length of the pixel has to travel to nearest sink or target (Llena et al., 2019; Schopper et al., 2019). $\mathrm{D}_{\text {up }}$ is calculated as follows:

$$
D_{u p}=\bar{w} \bar{s} \sqrt{A}
$$

Where $\overline{\mathrm{w}}$ and $\overline{\mathrm{s}}$ are average weighting and slope gradient $(\mathrm{m} / \mathrm{m})$ of the upslope contributing area, respectively and $\mathrm{A}$ is upslope contributing area $\left(\mathrm{m}^{2}\right)$. The $\mathrm{D}_{\mathrm{dn}}$ is computed as:

$$
D_{d n}=\sum_{i} \frac{d_{i}}{w_{i} s_{i}}
$$

158

Where $d_{i}$ is length of the pixel (i) along downslope (m), wi and $s_{i}$ are the weight and sloe of pixel (i), respectively.

Based on studies of Mayor et al. (2008), López-Vicente and Ben-Salem (2019), Schopper et al. (2019), and Sepehri et al. (2020), we computed $\mathrm{w}_{\mathrm{i}}$ using following equation:

$$
w_{i}=\left(1-\frac{(\text { Mean altitude }- \text { Altitude })}{\text { Range altitude }}\right)
$$

The altitude for each pixel through the case study can be extracted from DEM.

Stream power index (SPI): In hydrology studies, this parameter is known as bridge for connection between water flow paths, flow accumulations and slope(Chen and $\mathrm{Yu}, 2011$; Danielson, 2013; Regmi et al., 2014). This parameter can be calculated from digital elevation model (DEM) in ArcGIS10.7 using Eq. 6 (Nampak et al., 2014). At the specific point of the topographic surface, the higher values of the parameter show that surface water has more strength of erosive rather than lower values (Moore and Grayson, 1991).

$$
S P I=A_{s} \tan \beta
$$


Curvature: Curvature is the one of the mostly used morphometric factor which describe the shape of the ground surface (Il'Inskii and Yakimov, 1987). In this study, the parameter was extracting from DEM in ArcGIS 10.7. The value of the parameter varies from negative (concave areas) to until positive values (convex areas). Convex are the process of runoff is dominating and they are responsible for downslope flooding (Costache and Bui, 2020; Zaharia et al., 2017).

Curve number $(\boldsymbol{C N})$ : The $\mathrm{CN}$ is a conceptual and empirical parameter which developed in 1954 by the USDA Soil Conservation Service(Rallison, 1980). This parameter is a function of land use and hydrologic soil group which is used for determination of the potential runoff in hydrologic engineering and environmental impact analyses (Ponce and Hawkins, 1996).

\subsection{The Proposed F-BWM Model}

\subsubsection{Fuzzy Sets and triangular fuzzy numbers}

The subjective MCDA is sensitive to experts' judgments, causing difficultly evaluating the weights when the experts uses natural language such as "very better", "somewhat worse", or "so much better" to express a kind of general preferences(Hafezalkotob and Hafezalkotob, 2017). In mathematics, these natural languages are categorized as crisp sets. The concept of crisp sets only implied on full membership and non-membership, whereas in fuzzy set each elements can be partially membership(Boakai, 2016; Sepehri et al., 2019c). For the first time, the concept of fuzzy system was introduced and characterizedusing membership functions by Zadeh (1965) which grading membership between 0 and 1.In decision- making problems, the triangular fuzzy number (TFN) is one of the most used membership functions, which can be donated to triplet (l, m, u), wherel $<m<u$ (Dong et al., 2021; Guo and Zhao, 2017). Thetriangular fuzzy number is as follow: 


$$
\mu_{\tilde{A}}=\left\{\begin{aligned}
0, & x<l \\
\frac{x-l}{m-l}, & l \leq x \leq m \\
\frac{u-x}{u-m}, & m \leq x \leq u \\
0, & x \geq u
\end{aligned}\right.
$$

198

Where $1, \mathrm{~m}, \mathrm{u}$ are the lower, median and upper numbers of $\tilde{\mathrm{A}}$ (for the basic mathematical calculations of two TFNs, can be referred to (Carlsson and Fullér, 2001).

\subsubsection{Fuzzy best-worst method (F-BWM)}

Best-worst method (BWM) proposed by Rezaei (2015) is a new subjectively MCDA which can be used to derive optimal weights of criteria $\operatorname{set}\left\{c_{1}, c_{1}, \ldots, c_{j}, \ldots, c_{n}\right\}$. In this content, it is necessity to determine the best (e.g., the most favorable) and the worst (e.g., the least favorable) of criteria by experts. Afterwards, these criteria are compared relative to each other based on natural language. In F-BWM, it is necessity to transfer the natural language to fuzzy rating based on rules of transformation in Table. 1 (Dong et al., 2021; Guo and Zhao, 2017). The fuzzy comparison can be showed as follows:

$$
\tilde{A}=\left[\begin{array}{ccc}
\tilde{a}_{11} & \cdots & \tilde{a}_{1 n} \\
\vdots & \ddots & \vdots \\
\tilde{a}_{n 1} & \cdots & \tilde{a}_{n n}
\end{array}\right]
$$

Where each element of the matrix $\tilde{A}$ represent the relative importance of criterion i to criterion $\mathrm{j}, a_{i j}=(1,1,1)$ when $i=j$. It must be noted that in BWM method, there is no need to $\mathrm{n}$ fuzzy performance comparison to obtain a completed matrix $\tilde{A}$.

Table 1: Transformation rules of natural languages to membership functions

In the current study, the details of F-BWM algorithm to calculate the fuzzy weights can be brieflydescribed as follow(Dong et al., 2021; Guo and Zhao, 2017):

1. Provide a set of desired criteria $\left\{c_{1}, c_{1}, \ldots, c_{j}, \ldots, c_{n}\right\}$

2. Determine the best $\left(c_{B}\right)$ and worst $\left(c_{W}\right)$ criterion

3. Provide $\tilde{A_{B}}$ which showsfuzzy reference comparisons of $c_{B}$ over all the criteria.

$$
\tilde{A_{B}}=\left[\tilde{a}_{B 1}, \tilde{a}_{B 2}, \ldots, \tilde{a}_{B n}\right]
$$


217 Where $\tilde{a}_{B j}$ is the fuzzy preference of $c_{B}$ overc $c_{j}, \tilde{a}_{B j}=\left(a_{B j}^{l}, a_{B j}^{m}, a_{B j}^{u}\right), \mathrm{j}=1,2, \ldots, \mathrm{n}$ and $\tilde{a}_{B B}=$ $218(1,1,1)$

219

4. Provide $\tilde{A}_{W}$ which shows fuzzy reference comparisons of all the criteriaoverc ${ }_{W}$.

$$
\tilde{A}_{W}=\left[\tilde{a}_{1 W}, \tilde{a}_{2 W}, \ldots, \tilde{a}_{n W}\right]
$$

220

221

222

223

224

226

227

225

Where $\tilde{a}_{j W}$ is the fuzzy preference of $c_{j} \operatorname{over}_{B}, \tilde{a}_{j W}=\left(a_{j W}^{l}, a_{j W}^{m}, a_{j W}^{u}\right), \mathrm{j}=1,2, \ldots, \mathrm{n}$ and $\tilde{a}_{W W}=$ $(1,1,1)$

5. Determine the optimal fuzzy weight $\tilde{w}^{*}=\left[\tilde{w}_{1}^{*}, w_{2}^{*}, \ldots, w_{n}^{*}\right]$, where $\tilde{w}_{j}^{*}=$ $\left(w_{j}^{* l}, w_{j}^{* m}, w_{j}^{* u}\right)$ shows the optimal fuzzy weight of $c_{j}$ which is calculated using below model:

$$
\min \max _{j}\left\{\left|\frac{\tilde{w_{B}}}{\tilde{w_{j}}}-\tilde{a}_{B j}\right|,\left|\frac{\tilde{w_{j}}}{\tilde{w}_{w}}-\tilde{a}_{j w}\right|\right\}
$$

$$
\text { s.t. }\left\{\begin{array}{c}
\sum_{j=1}^{n} R\left(\widetilde{w}_{i}\right)=1 \\
l_{j}^{w} \leq m_{j}^{w} \leq u_{j}^{w} \\
l_{j}^{w} \geq 0 \\
j=1,2, \ldots, n
\end{array}\right.
$$

Where $\tilde{w}_{B}=\left(l_{B}^{w}, m_{B}^{w}, u_{B}^{w}\right), \quad \tilde{w_{j}}=\left(l_{j}^{w}, m_{j}^{w}, u_{j}^{w}\right), \quad \tilde{w}_{W}=\left(l_{W}^{w}, m_{W}^{w}, u_{W}^{w}\right), \quad \tilde{a}_{B j}=$ $\left(l_{B j}^{w}, m_{B j}^{w}, u_{B j}^{w}\right), \tilde{a}_{j W}=\left(l_{j W}^{w}, m_{j W}^{w}, u_{j W}^{w}\right)$ and $R\left(\widetilde{w}_{j}\right)=1 / 6\left(w_{j}^{l}+4 w_{j}^{m}+w_{j}^{u}\right)$

The above model can be transferred as below optimization model which are based on consistency ratio $(\xi)$ (next step).

$$
\min \tilde{\xi}
$$




$$
\text { s.t. }\left\{\begin{array}{c}
\left|\frac{\tilde{w_{B}}}{\tilde{w}_{j}}-\tilde{a}_{B j}\right| \leq \tilde{\xi} \\
\left|\frac{\tilde{w_{j}}}{\tilde{w}_{W}}-\tilde{a}_{j W}\right| \leq \tilde{\xi} \\
\sum_{j=1}^{n} R\left(\widetilde{w}_{j}\right)=1 \\
l_{j}^{w} \leq m_{j}^{w} \leq u_{j}^{w} \\
l_{j}^{w} \geq 0 \\
j=1,2, \ldots, n
\end{array}\right.
$$

231 Where $\tilde{\xi}=\left(l^{\xi}, m^{\xi}, u^{\xi}\right)$ and it can be assumed that $\tilde{\xi}^{*}=\left(k^{*}, k^{*}, k^{*}\right) \leq l^{\xi}$, then Eq. 12can be transferred as:

$$
\text { s.t. }\left\{\begin{array}{c}
\min \tilde{\xi}^{*} \\
\left|\frac{\left(l_{B}^{w}, m_{B}^{w}, u_{B}^{w}\right)}{\left(l_{j}^{w}, m_{j}^{w}, u_{j}^{w}\right)}-\left(l_{B j}, m_{B j}, u_{B j}\right)\right| \leq\left(k^{*}, k^{*}, k^{*}\right) \\
\left|\frac{\left(l_{j}^{w}, m_{j}^{w}, u_{j}^{w}\right)}{\left(l_{W}^{w}, m_{W}^{w}, u_{W}^{w}\right)}-\left(l_{j W}, m_{j W}, u_{j W}\right)\right| \leq\left(k^{*}, k^{*}, k^{*}\right) \\
\sum_{j=1}^{n} R\left(\widetilde{w}_{i}\right)=1 \\
l_{j}^{w} \leq m_{j}^{w} \leq u_{j}^{w} \\
l_{j}^{w} \geq 0 \\
j=1,2, \ldots, n
\end{array}\right.
$$

By solving above model, the optimal fuzzy weight $\left(\tilde{w}_{1}^{*}, \tilde{w}_{2}^{*}, \ldots, w_{n}^{*}\right)$ can be calculated.

6. Determine the consistency ratio using Eq. 14and Table. 2(its calculation is same as BWM (refer to Rezaei (2015)).

$$
\begin{gathered}
\xi^{2}-\left(1+2 \tilde{a}_{B W}\right) \xi+\left(\tilde{a}_{B W}^{2}-\tilde{a}_{B W}\right)=0, \text { Consistencyratio } \\
=\frac{\xi^{*}}{\text { consistenyindex }}
\end{gathered}
$$

Table 2: Consistency index (CI) values. 


\subsubsection{Removing scales of raster flood related-criteria}

242

243

\subsubsection{Transforming values of raster flood related-criteria to specific value}

The F-BWM is related to importance of criteria related to each other. It is obvious that the internal values of each criterion have difference importance of flood degree which must be considered. Also, apart En and $\mathrm{CN}$ criteria,the all used flood-related criteria are raster file (current format of ArcGIS10.7). In order to prioritize sub-watershed, it is necessity to transform raster file to a specific value which is proxy of flooding degree. To do this, the below algorithm was used.

- Reclassify the values of raster criteria for each sub-watershed

Each sub-catchment was divided into five clusters based on the IC values. To this end, a classification table was first prepared. The table's interval values were obtained from a subcatchment which has maximum standard deviation (SD). On the other hand, the table's boundary values, i.e. the minimum and maximum values of the table, were estimated based on the minimum and maximum IC values across all sub-catchments.

- Assigning a specific value of each sub-watershed

A specific value was assigned to each sub-catchment. To this end, BWM was used for pairwise comparisons and ranking was assigned to each class $\left(\kappa_{\mathrm{ij}}\right)$ based on the flooding degree by each IC class, in that the sediment production rate increases with increasing these indices (Table 3).Then, a specific value of $\mathrm{H}_{\mathrm{i}}$ was assigned to each sub-catchment using Eq. 15 .

$$
H_{i}=\sum_{j=1}^{5} \kappa_{i j} * x_{i j}
$$

Where $x_{i j}$ represents the area of under different classesrastercriteria (stage 1) rather than total area of case study, and index $\mathrm{i}$ and $\mathrm{j}$ are sub-watershed number and degree of IC (i.e., very low $(j=1)$, low $(j=2)$, moderate $(j=3)$, high $(j=4)$ and very high $(j=5))$.

- Determination of inter-criteria weighting 
The F-BWM is related to importance of criteria relative to each other. It is obvious that the internal values of each criterion have difference importance of flood degree which must be considered. After previous stage, since al all used criteria (both raster and vector criteria) had direct relationship of flood degree, the Eq. 16 was used to rescale all criteria which shows the inter-criteria weighting.

$$
R\left(w_{H i}\right)=\frac{H_{i}-\operatorname{Min}\left(H_{i=1: 32}\right)}{\operatorname{Max}\left(H_{i=1: 32}\right)-\operatorname{Min}\left(H_{i=1: 32}\right)}
$$

\subsection{Weighted overlay method (WOM)}

After assigning outer and inner criteria weighting, it is necessity to combination of both weights WOM due to having replacement property, was used (Eq. 17)(Raj and Shaji, 2017; Sepehri et al., 2020; Thapa et al., 2017). In the property, the lower weights of some criteria can be compensated for another criterion that has a higher weight.

$F H_{i=1: 32}=R\left(\widetilde{w}_{j}\right) * R\left(w_{H i}\right)$

\section{Results}

The statistical analysis of F-BWM has been used to prioritize sub-watersheds based on degree of flood hazard. In this regard, five flood-related criteria i.e. entropy of drainage network (C1), index of connectivity (C2), stream power index (C3), curvature (C4) and curve number (C5) were used. Based on experts' knowledge and field survey, the entropy of drainage network (c1) and curve number (c5) is considered as the best and worst criteria. Next, the fuzzy preferences to best criterion over other criteria (vector $\tilde{A_{B}}$ ) and all criteria over worst criteria (vector $\tilde{A_{W}}$ ) was determined. Then, based on step 5, the optimal fuzzy weight can be done to obtain the weights. 


$$
\text { s.t. }\left\{\begin{array}{l}
\left|\frac{\left(l_{1}^{w}, m_{1}^{w}, u_{1}^{w}\right)}{\left(l_{5}^{w}, m_{5}^{w}, u_{5}^{w}\right)}-\left(l_{15}, m_{15}, u_{15}\right)\right| \leq\left(k^{*}, k^{*}, k^{*}\right) \\
\left|\frac{\left(l_{1}^{w}, m_{1}^{w}, u_{1}^{w}\right)}{\left(l_{4}^{w}, m_{4}^{w}, u_{4}^{w}\right)}-\left(l_{14}, m_{14}, u_{14}\right)\right| \leq\left(k^{*}, k^{*}, k^{*}\right) \\
\left|\frac{\left(l_{1}^{w}, m_{1}^{w}, u_{1}^{w}\right)}{\left(l_{3}^{w}, m_{3}^{w}, u_{3}^{w}\right)}-\left(l_{13}, m_{13}, u_{13}\right)\right| \leq\left(k^{*}, k^{*}, k^{*}\right) \\
\cdot \\
\cdot \\
\mid \\
\left|\frac{\left(l_{5}^{w}, m_{5}^{w}, u_{5}^{w}\right)}{\left(l_{1}^{w}, m_{1}^{w}, u_{1}^{w}\right)}-\left(l_{55}, m_{55}, u_{55}\right)\right| \leq\left(k^{*}, k^{*}, k^{*}\right) \\
\left|\frac{\left(l_{4}^{w}, m_{4}^{w}, u_{4}^{w}\right)}{\left(l_{1}^{w}, m_{1}^{w}, u_{1}^{w}\right)}-\left(l_{45}, m_{45}, u_{45}\right)\right| \leq\left(k^{*}, k^{*}, k^{*}\right) \\
\left|\frac{\left(l_{3}^{w}, m_{3}^{w}, u_{3}^{w}\right)}{\left(l_{1}^{w}, m_{1}^{w}, u_{1}^{w}\right)}-\left(l_{35}, m_{35}, u_{35}\right)\right| \leq\left(k^{*}, k^{*}, k^{*}\right)
\end{array}\right.
$$

290

The above nonlinearity optimization problem can be transferred as crisp values, as follow:

$\min k^{*}$

$$
\text { s.t. }\left\{\begin{array}{c}
l_{1}-4 * u_{5} \leq k ; l_{1}-4 * u_{5} \geq-k \\
m_{1}-5 * m_{5} \leq k ; m_{1}-5 * m_{5} \geq-k \\
u_{1}-6 * l_{5} \leq k ; u_{1}-6 * l_{5} \geq-k \\
l_{1}-3 * u_{4} \leq k ; l_{1}-3 * u_{4} \geq-k \\
m_{1}-4 * m_{4} \leq k ; m_{1}-4 * m_{4} \geq-k \\
u_{1}-5 * l_{4} \leq k ; u_{1}-5 * l_{4} \geq-k \\
\ldots \\
l_{4}-1 * u_{1} \leq k ; l_{4}-1 * u_{1} \geq-k \\
m_{4}-2 * m_{1} \leq k ; m_{4}-2 * m_{1} \geq-k \\
u_{4}-3 * l_{1} \leq k ; u_{4}-3 * l_{1} \geq-k \\
l_{3}-2 * u_{1} \leq k ; l_{3}-2 * u_{1} \geq-k \\
m_{3}-3 * m_{1} \leq k ; m_{3}-3 * m_{1} \geq-k \\
u_{3}-4 * l_{1} \leq k ; u_{3}-4 * l_{1} \geq-k \\
\frac{1}{6} * l_{1}+\frac{1}{6} * 4 * m_{1}+\frac{1}{6} * u_{1}+\cdots+ \\
\frac{1}{6} * l_{5}+\frac{1}{6} * 4 * m_{5}+\frac{1}{6} * u_{5}=1 \\
l_{1} \geq m_{1} \geq u_{1} ; \ldots ; l_{5} \geq m_{5} \geq u_{5} \\
l_{1} \geq 0 ; \ldots, l_{5} \geq 0 \\
k \geq 0
\end{array}\right.
$$

293 By solving above optimization problem, the weights of used flood-related criteria were determined. 


\subsection{Analysis of inter-criteria weighting}

In order to determine the entropy (EN) for each of the 31 sub-watersheds, a box counting method was used, with the size of boxes being about $0.08 \mathrm{~mm} \times 0.08 \mathrm{~mm}$ until $168.66 \mathrm{~mm} \times$ $168.66 \mathrm{~mm}$. Then, the number of boxes in which the river network was present was calculated. Finally, the EN criterion values of each sub-watershed were determined with respect to the changes in counting of boxes (Fig. 3). The final results show that the sub-watershed 5 has the highest EN value (1.4) among other sub-watersheds. According to Fig. 1, the drainage network of this sub-watershed has the greatest branch and complexity. After calculating EN values of each sub-watershed, the all values were rescaled by using Eq. 16 which shows the inter-criteria weighting for each sub-watershed (Table 4).

Fig. 3a: doing algorithm of box-counting method and,b: calculating EN based on boxcounting method

For calculating the inter-criteria weighting for IC, SPI and curvature criteria, the algorithm which was mentioned in section 4.3 , was used. For example in IC criterion, after calculating the IC for each sub-watershed (Fig. 4), the results showed that the sub-watershed 29 has the maximum value of SD (0.91) and the other and the sub-watersheds 13(-1.65)and 20 (10.86)have the maximum and minimum values of IC through all sub-watersheds. Therefore, for preparing the classification table to reclassify values of IC for each sub-watershed, the values of sub-watershed 29 were used for internal values of classification table and maximum and minimum values of IC regarding IC index were used for boundary conditions of classification table(Fig. 4). The IC classification table can be shown as very low (-10.85 to - 
7.19), low (-7.19 to -6.19$)$, moderate (-6.19 to -5.40$)$, high (-5.40 to -4.65$)$ and very high $(-4.65$

322

323

324

to -1.57). After classifying the values of IC into five degrees of IC, a special weight using BWM method which varies from 0.06 and 0.41 was assigned to each class based on importance of it on rate of flooding degree and then by using Eqs. 15 and 16, final weight if IC for each sub-watershed was determined (the process of weighting of curvature and SPI is similar to IC (Tables 5: 7). Regarding $\mathrm{CN}$ criterion, the value of $\mathrm{CN}$ for each sub-watershed which was prepared for general department of natural resources of Hamadan province by using Eq. 16, the final weight for each sub-watershed was determined.

Fig. 4: IC Values for sub-watersheds

Table 4: Assigning inter-criteria weighting to EN index

Table 5: Assigning inter/outer-criteria weighting to IC index Table 6: Assigning inter/outer-criteria weighting to curvature index

\subsection{Flood magnitude prioritization}

After calculating the weights of criteria, the flood prioritization was provided by integration of criteria in WOM method (Fig. 5).

$$
\begin{gathered}
F H_{i=1: 32}=R_{E N}\left(\widetilde{w}_{j}\right) * R_{E N}\left(w_{H i}\right)+R_{I C}\left(\widetilde{w}_{j}\right) * R_{I C}\left(w_{H i}\right)+R_{S P I}\left(\widetilde{w}_{j}\right) * R_{S P I}\left(w_{H i}\right)+R_{C U}\left(\widetilde{w}_{j}\right) \\
* R_{C U}\left(w_{H i}\right)+R_{C N}\left(\widetilde{w}_{j}\right) * R_{C N}\left(w_{H i}\right)
\end{gathered}
$$

\section{Discussion}

In watershed scale, the sub-watersheds based on their morphometric and hydrologic properties have different hydrological behavior regarding flood degree, erosion and sedimentation. Therefore, prioritization of sub-watershed is known as crucial step for watershed management strategies. Subjective MCDA is mostly used methods for flood prioritization. These methods based on Smithson (2012) are categorized as knowledge-based methods, so that the results of 
desired study are function of experts' decision, leading to high uncertainty of results. In this regard, BWM can be used as efficiency method to reduce the number of experts' decision (Rezaei, 2015). However, the existence of qualitative judgments on BWM (i.e. 9-point table) can be considered as one of the main sources of uncertainty in this method, therefore, in this study we used TFN to nearly resolve the drawback of qualitative judgments (Bellman and Zadeh, 1970; Guo and Zhao, 2017; Zhao and Guo, 2014, 2015).

Fig. 4 shows the results of F-BWM in flood prioritization. Based on the figure, the land used of sub-watershed 14 is composed as rock and rangeland III, leading to high value of CN, IC. Also, on the other hand the drainage network of the sub-watershed has the maximum entropy value of all sub-watersheds. On the contrary, the sub-watershed 15 has located in final rank of flood prioritization. In this sub-watershed due to existence of straight drainage networks, the value of the entropy of drainage network as most flood-related criteria has located in minimum level.

\section{Conclusion}

In the current study, five flood-related criteria i.e. EN, IC, CN, curvature and SPI were used to flood prioritization in the case study. In this regard, F-BWM as knowledge-based method was used to assigning initial weights to criteria and combination them to earn flood degree. The conclusion can be drawn that the EN is the most important flood-related criterion, so that the point which must be considered is related to consequences of flood events which known as flood risk. In this state, the critical sub-watersheds can be better recognized for doing watershed management strategies. 
373 Data availability: The datasets used and/or analyzed during the current study are available

374 from the corresponding author on reasonable request.

\section{Compliance with ethical standards}

376 Ethics approval and consent to participate: Not applicable.

377 Consent for publication: Not applicable.

378 Competing interests: The authors declare that they have no competing interests.

\section{References}

Abdullah, T.O., Ali, S.S., Al-Ansari, N.A., Knutsson, S., 2018. Possibility of Groundwater Pollution in Halabja Saidsadiq Hydrogeological Basin, Iraq Using Modified DRASTIC Model Based on AHP and Tritium Isotopes. Geosciences 8, 236.

Adhikari, P., Hong, Y., Douglas, K.R., Kirschbaum, D.B., Gourley, J., Adler, R., Brakenridge, G.R., 2010. A digitized global flood inventory (1998-2008): compilation and preliminary results. Natural Hazards 55, 405-422.

Aher, P., Adinarayana, J., Gorantiwar, S., 2014. Quantification of morphometric characterization and prioritization for management planning in semi-arid tropics of India: a remote sensing and GIS approach. Journal of Hydrology 511, 850-860.

Akay, H., Koçyiğit, M.B., 2020. Flash flood potential prioritization of sub-basins in an ungauged basin in Turkey using traditional multi-criteria decision-making methods. Soft Computing, 1-13.

Ali, A., Rashid, T., 2019. Hesitant fuzzy best-worst multi-criteria decision-making method and its applications. International Journal of Intelligent Systems 34, 1953-1967.

Almasi, P., Soltani, S., 2017. Assessment of the climate change impacts on flood frequency (case study: Bazoft Basin, Iran). Stochastic Environmental Research and Risk Assessment 31, 1171-1182.

Anees, M.T., Abdullah, K., Nawawi, M., A. Rahman, N.N.N., Ismail, A.Z., Syakir, M., Abdul Kadir, M.O., 2019. Prioritization of Flood Vulnerability Zones Using Remote Sensing and GIS for Hydrological Modelling. Irrigation and Drainage 68, 176-190.

Arabameri, A., Rezaei, K., Cerdà, A., Conoscenti, C., Kalantari, Z., 2019. A comparison of statistical methods and multi-criteria decision making to map flood hazard susceptibility in Northern Iran. Science of the Total Environment 660, 443-458.

Ariza-Villaverde, A., Jiménez-Hornero, F., de Ravé, E.G., 2013. Multifractal analysis applied to the study of the accuracy of DEM-based stream derivation. Geomorphology 197, 85-95.

Babaei, S., Ghazavi, R., Erfanian, M., 2018. Urban flood simulation and prioritization of critical urban sub-catchments using SWMM model and PROMETHEE II approach. Physics and Chemistry of the Earth, Parts A/B/C 105, 3-11.

Bahrami, Y., Hassani, H., Maghsoudi, A., 2020. Landslide susceptibility mapping using AHP and fuzzy methods in the Gilan province, Iran. GeoJournal, 1-20.

Bellman, R.E., Zadeh, L.A., 1970. Decision-making in a fuzzy environment. Management science 17, B141-B-164.

Boakai, S., 2016. A fuzzy best-worst multi-criteria decision-making method for third-party logistics provider selection.

Borselli, L., Cassi, P., Torri, D., 2008. Prolegomena to sediment and flow connectivity in the landscape: a GIS and field numerical assessment. Catena 75, 268-277. 
Calsamiglia, A., Fortesa, J., García-Comendador, J., Lucas-Borja, M.E., Calvo-Cases, A., Estrany, J., 2018. Spatial patterns of sediment connectivity in terraced lands: Anthropogenic controls of catchment sensitivity. Land Degradation \& Development 29, 1198-1210. Carlsson, C., Fullér, R., 2001. On possibilistic mean value and variance of fuzzy numbers. Fuzzy sets and systems $122,315-326$. Chen, C.-Y., Yu, F.-C., 2011. Morphometric analysis of debris flows and their source areas using GIS. Geomorphology 129, 387-397. Chen, W., Hong, H., Li, S., Shahabi, H., Wang, Y., Wang, X., Ahmad, B.B., 2019. Flood susceptibility modelling using novel hybrid approach of reduced-error pruning trees with bagging and random subspace ensembles. Journal of Hydrology 575, 864-873.

Chitsaz, N., Banihabib, M.E., 2015. Comparison of different multi criteria decision-making models in prioritizing flood management alternatives. Water Resources Management 29, 2503-2525.

Costache, R., Bui, D.T., 2020. Identification of areas prone to flash-flood phenomena using multiplecriteria decision-making, bivariate statistics, machine learning and their ensembles. Science of The Total Environment 712, 136492. Power Index (SPI) for the Gilmore creek watershed in Winona County, Minnesota. Papers in resource analysis 15 .

Das, B., Pal, S.C., 2020. Assessment of groundwater vulnerability to over-exploitation using MCDA, AHP, fuzzy logic and novel ensemble models: a case study of Goghat-I and II blocks of West Bengal, India. Environmental Earth Sciences 79, 1-16.

Dash, P., Sar, J., 2020. Identification and validation of potential flood hazard area using GIS-based multi-criteria analysis and satellite data-derived water index. Journal of Flood Risk Management.

Dehghanian, N., Saeid Mousavi Nadoushani, S., Saghafian, B., Damavandi, M.R., 2020. Evaluation of coupled ANN-GA model to prioritize flood source areas in ungauged watersheds. Hydrology Research 51, 423-442.

440 Dong, J., Wan, S., Chen, S.-M., 2021. Fuzzy best-worst method based on triangular fuzzy numbers for multi-criteria decision-making. Information Sciences 547, 1080-1104.

Fan, J., Li, M., Guo, F., Yan, Z., Zheng, X., Zhang, Y., Xu, Z., Wu, F., 2018. Priorization of River Restoration by Coupling Soil and Water Assessment Tool (SWAT) and Support Vector Machine (SVM) Models in the Taizi River Basin, Northern China. International journal of environmental research and public health 15, 2090.

Farokhzadeh, B., Ildoromi, A., Attaeian, B., Nourouzi, M., 2015. Assessment the estimation of suspended load under the influence of land use change using SWAT model (Case study: Yalfan watershed). Environmental Erosion Research Journal 5, 28-46.

Fernández, D., Lutz, M., 2010. Urban flood hazard zoning in Tucumán Province, Argentina, using GIS and multicriteria decision analysis. Engineering Geology 111, 90-98.

Field, C.B., Barros, V., Stocker, T.F., Dahe, Q., 2012. Managing the risks of extreme events and disasters to advance climate change adaptation: special report of the intergovernmental panel on climate change. Cambridge University Press.

Fryirs, K., 2013. (Dis) Connectivity in catchment sediment cascades: a fresh look at the sediment delivery problem. Earth Surface Processes and Landforms 38, 30-46.

Ghaleno, M.R.D., Meshram, S.G., Alvandi, E., 2020. Pragmatic approach for prioritization of flood and sedimentation hazard potential of watersheds. Soft Computing, 1-14.

Guo, S., Zhao, H., 2017. Fuzzy best-worst multi-criteria decision-making method and its applications. Knowledge-Based Systems 121, 23-31.

Hafezalkotob, A., Hafezalkotob, A., 2017. A novel approach for combination of individual and group decisions based on fuzzy best-worst method. Applied Soft Computing 59, 316-325.

Hajian, F., Dykes, A.P., Cavanagh, S., 2019. Assessment of the flood hazard arising from land use change in a forested catchment in northern Iran. Journal of flood risk management 12, e12481. 
Hazarika, N., Barman, D., Das, A., Sarma, A., Borah, S., 2018. Assessing and mapping flood hazard, vulnerability and risk in the Upper Brahmaputra River valley using stakeholders' knowledge and multicriteria evaluation (MCE). Journal of Flood Risk Management 11, S700-S716. Heckmann, T., Cavalli, M., Cerdan, O., Foerster, S., Javaux, M., Lode, E., Smetanová, A., Vericat, D., Brardinoni, F., 2018. Indices of sediment connectivity: opportunities, challenges and limitations. EarthScience Reviews 187, 77-108. evidence and data mining techniques in construction of flood susceptibility map of Poyang County, China. Science of the total environment 625, 575-588.

Hooshyaripor, F., Faraji-Ashkavar, S., Koohyian, F., Tang, Q., Noori, R., 2020. Annual flood damage influenced by El Niño in the Kan River basin, Iran. Natural Hazards and Earth System Sciences 20, 27392751.

II'Inskii, N., Yakimov, N., 1987. Determination of the shape of the downstream slope of an earth-fill dam from the seepage strength conditions at the face. Fluid Dynamics 22, 414-419. Ildoromi, A.R., Sepehri, M., Malekinezhad, H., Kiani-Harchegani, M., Ghahramani, A., Hosseini, S.Z., Artimani, M.M., 2019. Application of Multi-Criteria Decision Making and GIS for Check Dam Layout in the Ilanlu Basin, Northwest of Hamadan Province, Iran. Physics and Chemistry of the Earth, Parts $\mathrm{A} / \mathrm{B} / \mathrm{C}$.

481 Kayastha, P., Dhital, M.R., De Smedt, F., 2013. Application of the analytical hierarchy process (AHP) for landslide susceptibility mapping: a case study from the Tinau watershed, west Nepal. Computers \& Geosciences 52, 398-408.

Lin, K., Chen, H., Xu, C.-Y., Yan, P., Lan, T., Liu, Z., Dong, C., 2020. Assessment of flash flood risk based on improved analytic hierarchy process method and integrated maximum likelihood clustering algorithm. Journal of Hydrology 584, 124696.

Llena, M., Vericat, D., Cavalli, M., Crema, S., Smith, M., 2019. The effects of land use and topographic changes on sediment connectivity in mountain catchments. Science of the Total Environment 660, 899-912.

López-Vicente, M., Ben-Salem, N., 2019. Computing structural and functional flow and sediment connectivity with a new aggregated index: A case study in a large Mediterranean catchment. Science of the Total Environment 651, 179-191.

Mahmoud, S.H., Gan, T.Y., 2018. Multi-criteria approach to develop flood susceptibility maps in arid regions of Middle East. Journal of cleaner production 196, 216-229.

Malekinezhad, H., Talebi, A., Ilderomi, A.R., Hosseini, S.Z., Sepehri, M., 2017. Flood hazard mapping using fractal dimension of drainage network in Hamadan City, Iran. Journal of Environmental Engineering and Science 12, 86-92.

Mayor, Á.G., Bautista, S., Small, E.E., Dixon, M., Bellot, J., 2008. Measurement of the connectivity of runoff source areas as determined by vegetation pattern and topography: A tool for assessing potential water and soil losses in drylands. Water Resources Research 44.

Mishra, A., Kar, S., Singh, V., 2007. Prioritizing structural management by quantifying the effect of land use and land cover on watershed runoff and sediment yield. Water Resources Management 21, 18991913.

Moore, I.D., Grayson, R.B., 1991. Terrain-based catchment partitioning and runoff prediction using vector elevation data. Water Resources Research 27, 1177-1191.

Myronidis, D., Papageorgiou, C., Theophanous, S., 2016. Landslide susceptibility mapping based on landslide history and analytic hierarchy process (AHP). Natural Hazards 81, 245-263.

Nampak, H., Pradhan, B., Abd Manap, M., 2014. Application of GIS based data driven evidential belief function model to predict groundwater potential zonation. Journal of Hydrology 513, 283-300.

Ponce, V.M., Hawkins, R.H., 1996. Runoff curve number: Has it reached maturity? Journal of hydrologic engineering 1, 11-19. 
Rahmati, O., Haghizadeh, A., Stefanidis, S., 2016. Assessing the accuracy of GIS-based analytical hierarchy process for watershed prioritization; Gorganrood River Basin, Iran. Water resources management 30, 1131-1150. Raj, D., Shaji, E., 2017. Fluoride contamination in groundwater resources of Alleppey, southern India. Geoscience Frontiers 8, 117-124. Rallison, R.E., 1980. Origin and evolution of the SCS runoff equation, Symposium on watershed management 1980. ASCE, pp. 912-924. 2014. Application of frequency ratio, statistical index, and weights-of-evidence models and their comparison in landslide susceptibility mapping in Central Nepal Himalaya. Arabian Journal of Geosciences 7, 725-742.

Rezaei, J., 2015. Best-worst multi-criteria decision-making method. Omega 53, 49-57.

Saaty, T., 1980. The Analytic Hierarchy Process:, New York, NY, McGraw Hill, reprinted by RWS Publication, Pittsburgh.

Sarhadi, A., Soltani, S., Modarres, R., 2012. Probabilistic flood inundation mapping of ungauged rivers: Linking GIS techniques and frequency analysis. Journal of Hydrology 458, 68-86.

Schopper, N., Mergili, M., Frigerio, S., Cavalli, M., Poeppl, R., 2019. Analysis of lateral sediment connectivity and its connection to debris flow intensity patterns at different return periods in the Fella River system in northeastern Italy. Science of The Total Environment 658, 1586-1600.

Sener, E., Davraz, A., 2013. Assessment of groundwater vulnerability based on a modified DRASTIC model, GIS and an analytic hierarchy process (AHP) method: the case of Egirdir Lake basin (Isparta, Turkey). Hydrogeology Journal 21, 701-714.

Sepehri, M., Ildoromi, A.R., Malekinezhad, H., Ghahramani, A., Ekhtesasi, M.R., Cao, C., KianiHarchegani, M., 2019a. Assessment of check dams' role in flood hazard mapping in a semi-arid environment. Geomatics, Natural Hazards and Risk 10, 2239-2256.

Sepehri, M., Ildoromi, A.R., Malekinezhad, H., Hosseini, S.Z., Talebi, A., Goodarzi, S., 2017. Flood hazard mapping for the gonbad chi region, Iran. Journal of Environmental Engineering and Science 12, 16-24. Sepehri, M., Malekinezhad, H., Hosseini, S.Z., Ildoromi, A.R., 2019b. Assessment of flood hazard mapping in urban areas using entropy weighting method: a case study in Hamadan city, Iran. Acta Geophysica 67, 1435-1449.

Sepehri, M., Malekinezhad, H., Hosseini, S.Z., Ildoromi, A.R., 2019c. Suburban flood hazard mapping in Hamadan city, Iran, Proceedings of the Institution of Civil Engineers-Municipal Engineer. Thomas Telford Ltd, pp. 1-13.

Sepehri, M., Malekinezhad, H., Jahanbakhshi, F., Ildoromi, A.R., Chezgi, J., Ghorbanzadeh, O., Naghipour, E., 2020. Integration of interval rough AHP and fuzzy logic for assessment of flood prone areas at the regional scale. Acta Geophysica.

Shivhare, N., Rahul, A.K., Omar, P.J., Chauhan, M.S., Gaur, S., Dikshit, P.K.S., Dwivedi, S.B., 2018. Identification of critical soil erosion prone areas and prioritization of micro-watersheds using geoinformatics techniques. Ecological Engineering 121, 26-34.

Smith, K., Ward, R., 1998. Mitigating and managing flood losses. Floods: Physical Processes and Human Impacts (Chichester: John Wiley \& Sons).

Smithson, M., 1989. Cognitive Science. Ignorance and uncertainty: Emerging paradigms. New York, NY, US. Springer-Verlag Publishing. http://dx. doi. org/10.1007/978-1-4612-3628-3.

Smithson, M., 2012. Ignorance and uncertainty: emerging paradigms. Springer Science \& Business Media.

Swain, K.C., Singha, C., Nayak, L., 2020. Flood Susceptibility Mapping through the GIS-AHP Technique Using the Cloud. ISPRS International Journal of Geo-Information 9, 720.

Talebi, A., Abyari, E., Parvizi, S., 2019a. Prioritization of Sub-Watersheds from Flooding Viewpoint Using the SWAT Model (Arazkoose Watershed, Golestan Province). JWSS-Isfahan University of Technology 23, 409-419. 
Talebi, A., ESLAMI, Z., Abbasi, A., 2019b. Comparing prioritization from flooding of sub-basins using HEC-HMS model and experimental methods in Eskandari Watershed. Tehrany, M.S., Pradhan, B., Jebur, M.N., 2014. Flood susceptibility mapping using a novel ensemble weights-of-evidence and support vector machine models in GIS. Journal of hydrology 512, 332-343. Termeh, S.V.R., Kornejady, A., Pourghasemi, H.R., Keesstra, S., 2018. Flood susceptibility mapping using novel ensembles of adaptive neuro fuzzy inference system and metaheuristic algorithms. Science of the Total Environment 615, 438-451. Thapa, R., Gupta, S., Reddy, D., 2017. Application of geospatial modelling technique in delineation of fluoride contamination zones within Dwarka Basin, Birbhum, India. Geoscience Frontiers 8, 11051114. Veltri, M., Veltri, P., Maiolo, M., 1996. On the fractal description of natural channel networks. Journal of hydrology 187, 137-144. S.N., Magilligan, F.J., 2019. Connectivity as an emergent property of geomorphic systems. Earth Surface Processes and Landforms 44, 4-26. journal of occupational and environmental medicine 10, 54. Zadeh, L.A., 1965. Fuzzy sets. Information and control 8, 338-353. indices: a methodological approach to identifying areas susceptible to flood and flooding risk. Case study: the Prahova catchment (Romania). Frontiers of Earth Science 11, 229-247. Zhang, S., Guo, Y., Wang, Z., 2015. Correlation between flood frequency and geomorphologic complexity of rivers network-a case study of Hangzhou China. Journal of Hydrology 527, 113-118. Zhao, H., Guo, S., 2014. Selecting green supplier of thermal power equipment by using a hybrid MCDM method for sustainability. Sustainability 6, 217-235.

588 Zhao, H., Guo, S., 2015. External benefit evaluation of renewable energy power in China for 589 sustainability. Sustainability 7, 4783-4805.

590 Zou, Q., Zhou, J., Zhou, C., Song, L., Guo, J., 2013. Comprehensive flood risk assessment based on set Assessment 27, 525-546. 


\section{Figures}
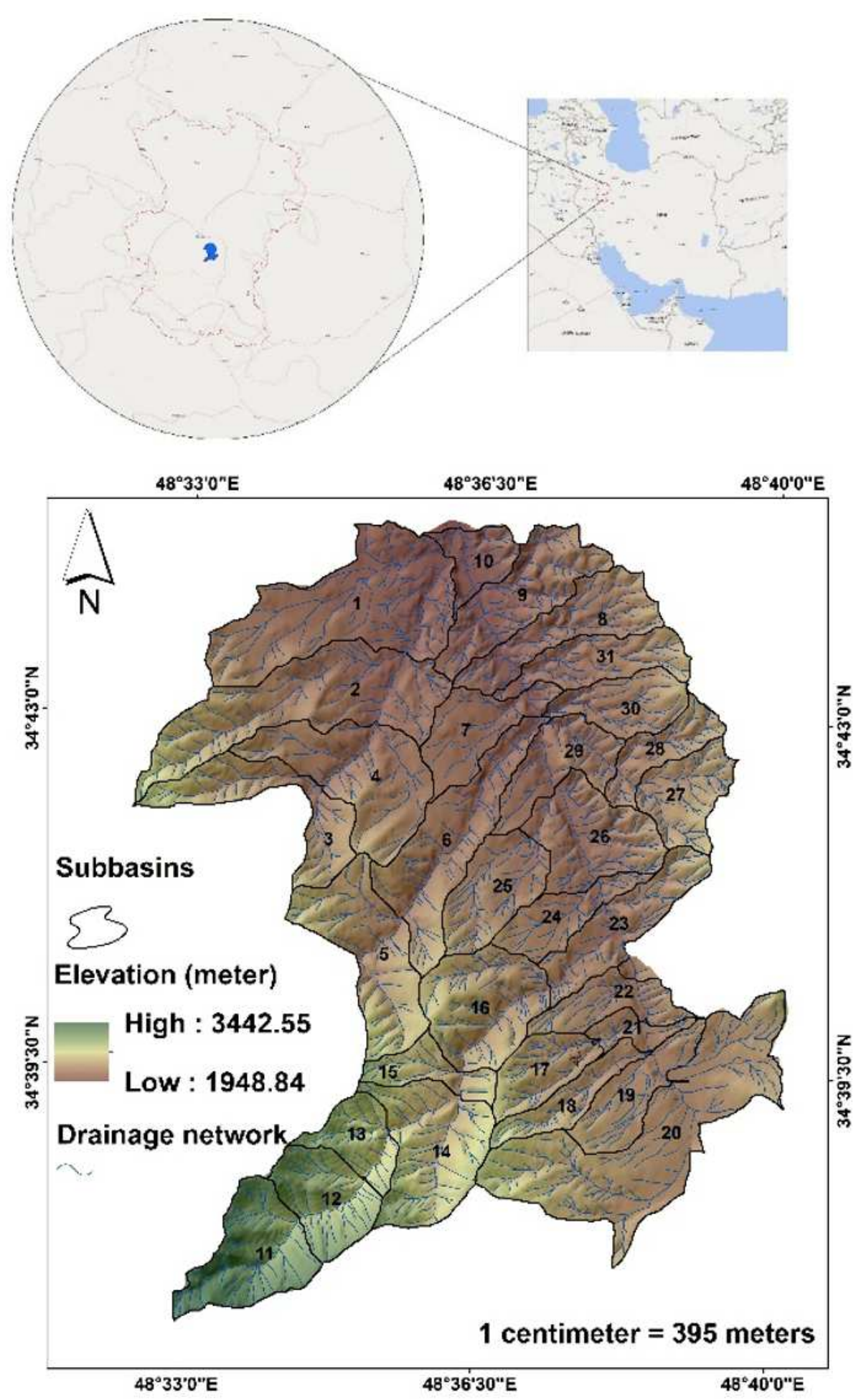

Figure 1

location of the case study Note: The designations employed and the presentation of the material on this map do not imply the expression of any opinion whatsoever on the part of Research Square concerning 
the legal status of any country, territory, city or area or of its authorities, or concerning the delimitation of its frontiers or boundaries. This map has been provided by the authors.

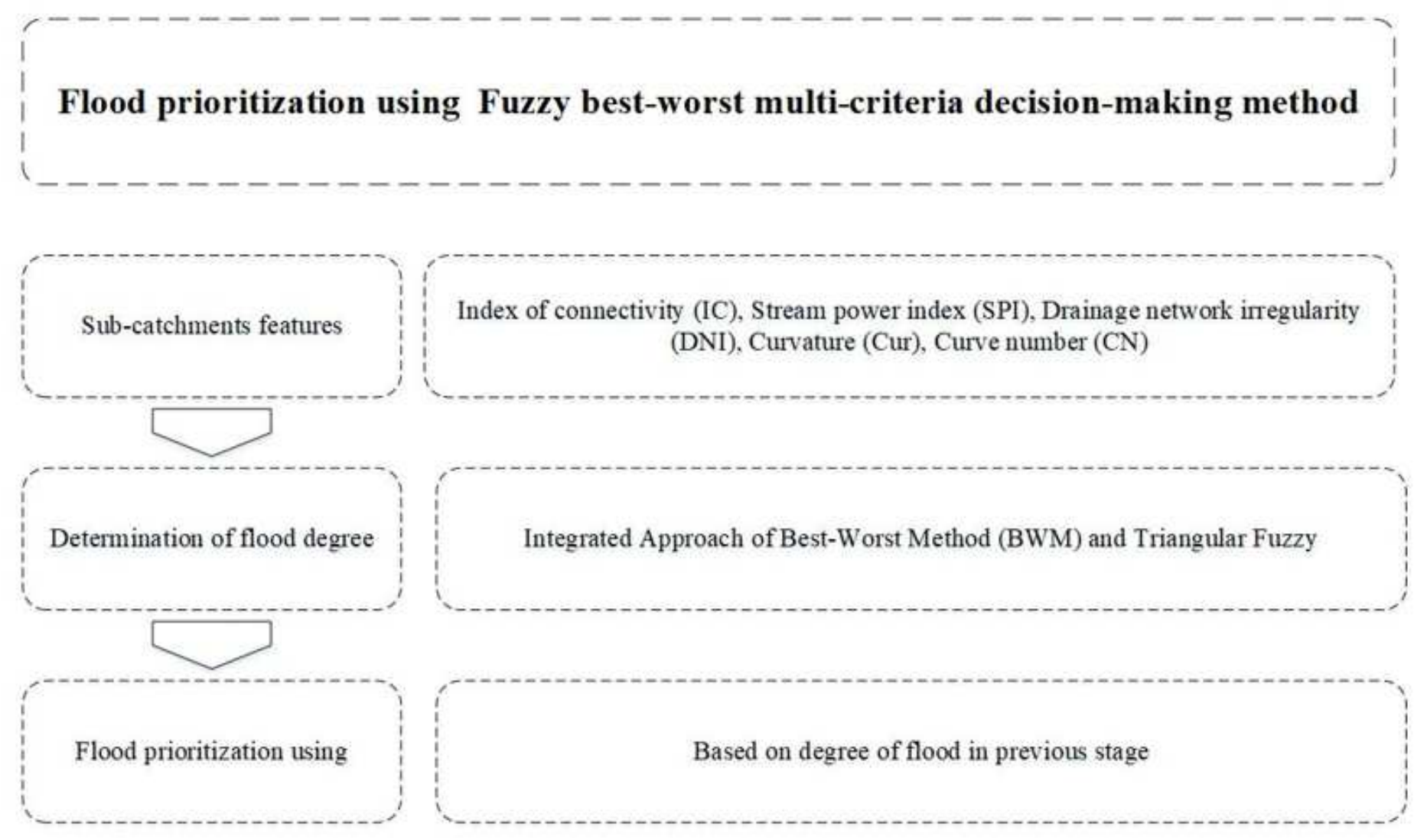

Figure 2

flowchart of the used methodology 


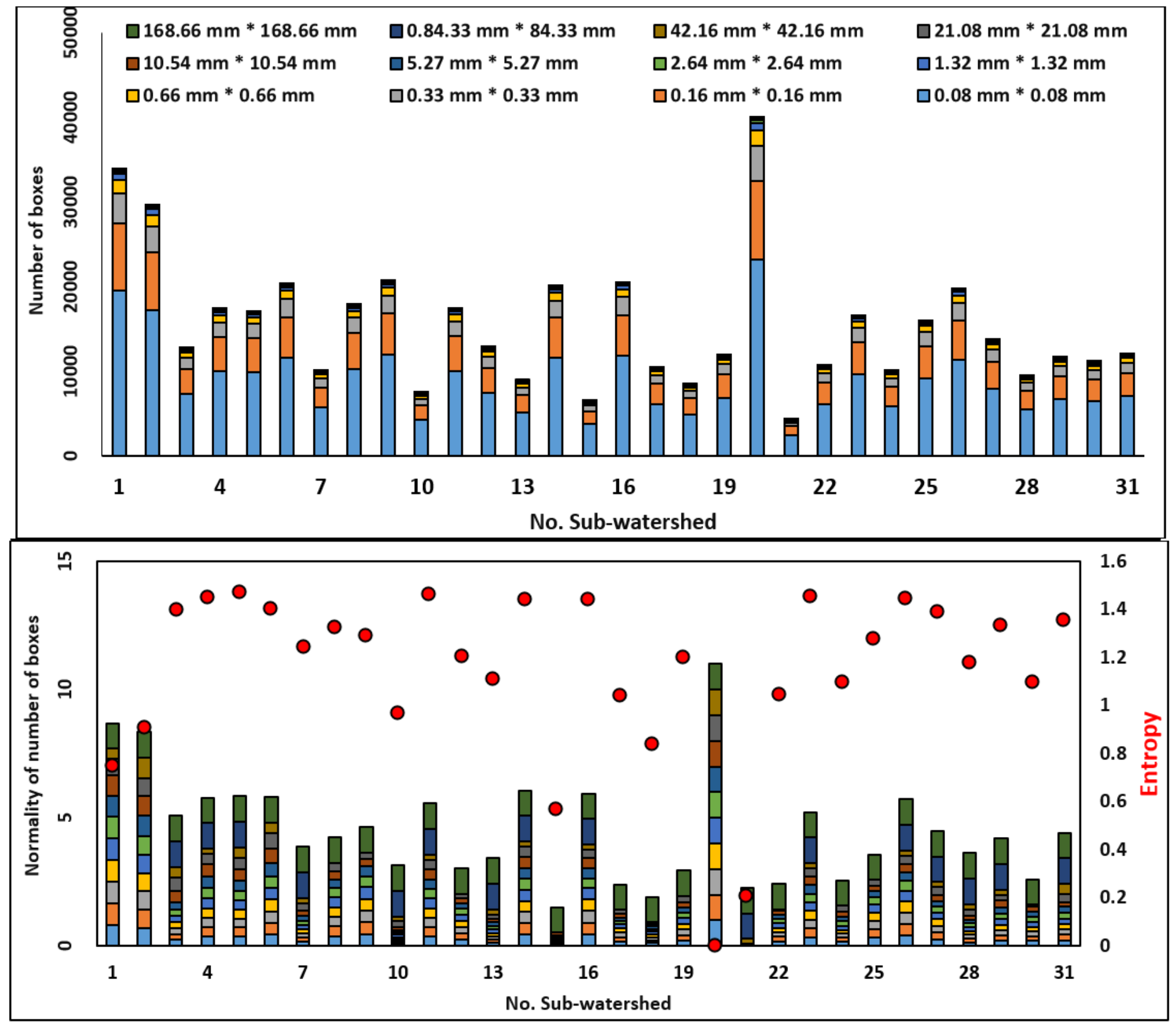

Figure 3

a: doing algorithm of box-counting method and, b: calculating EN based on box-counting method 

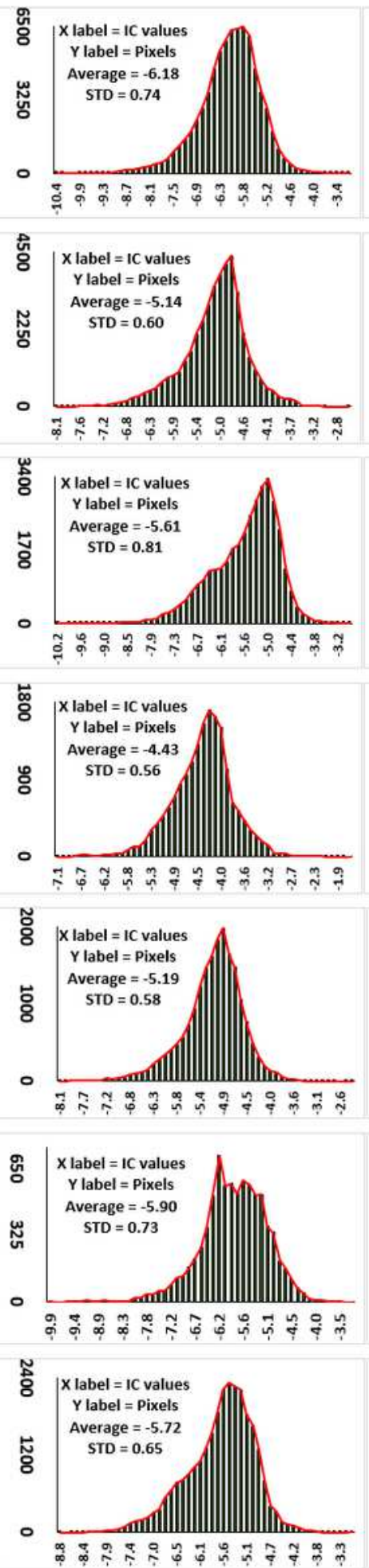
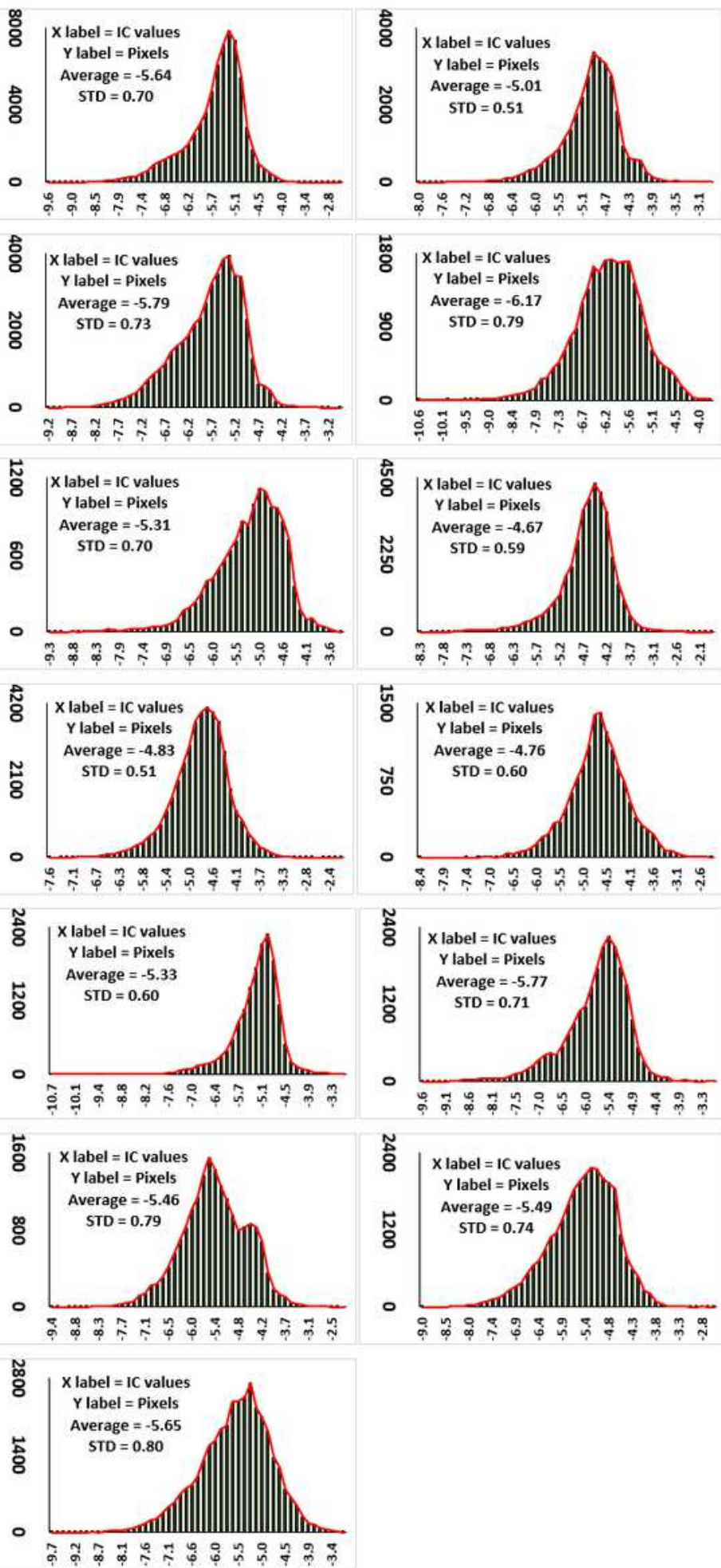
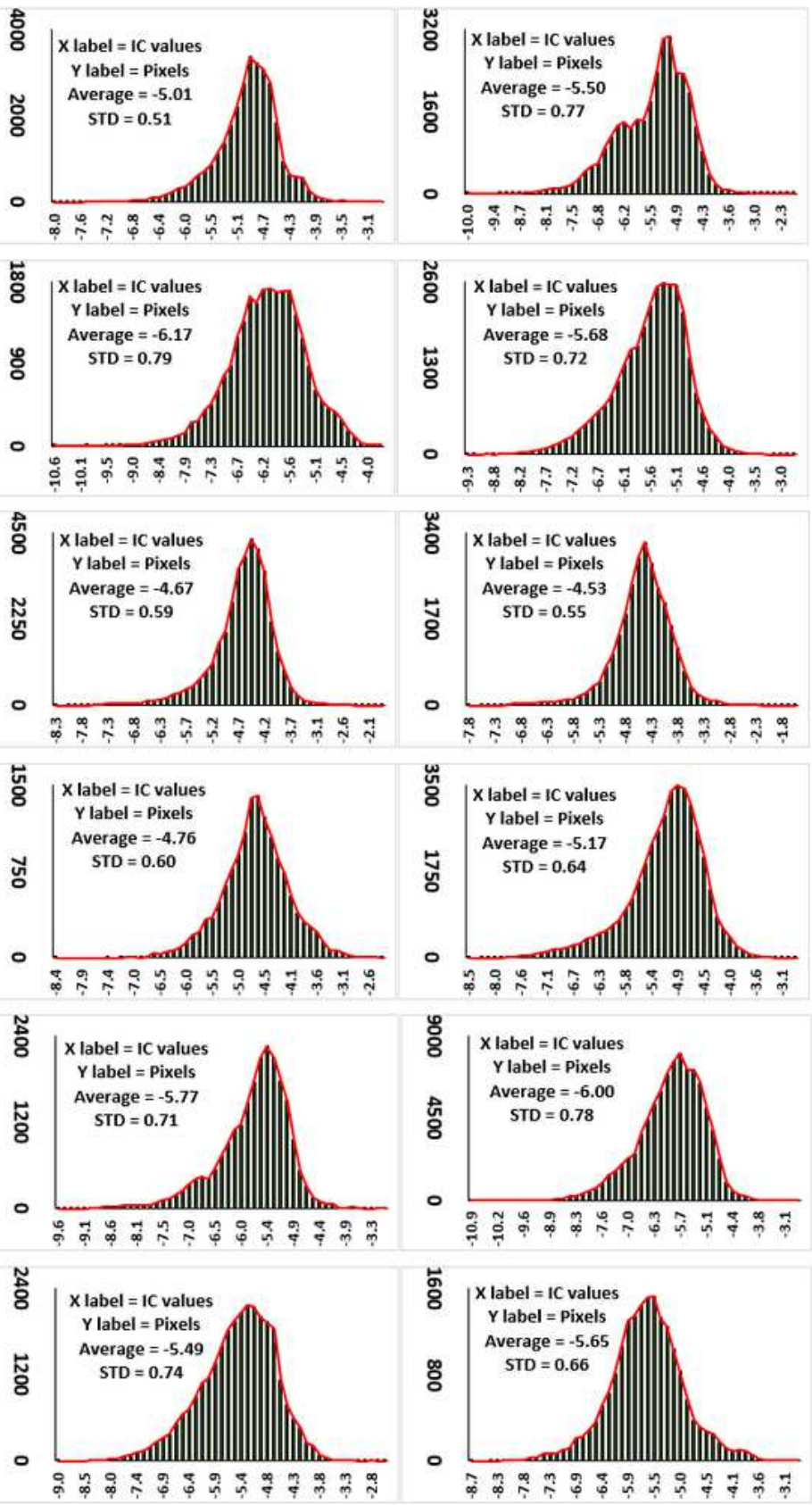

Figure 4

IC Values for sub-watersheds (Right to left is No. 1 to No. 31, respectively) 


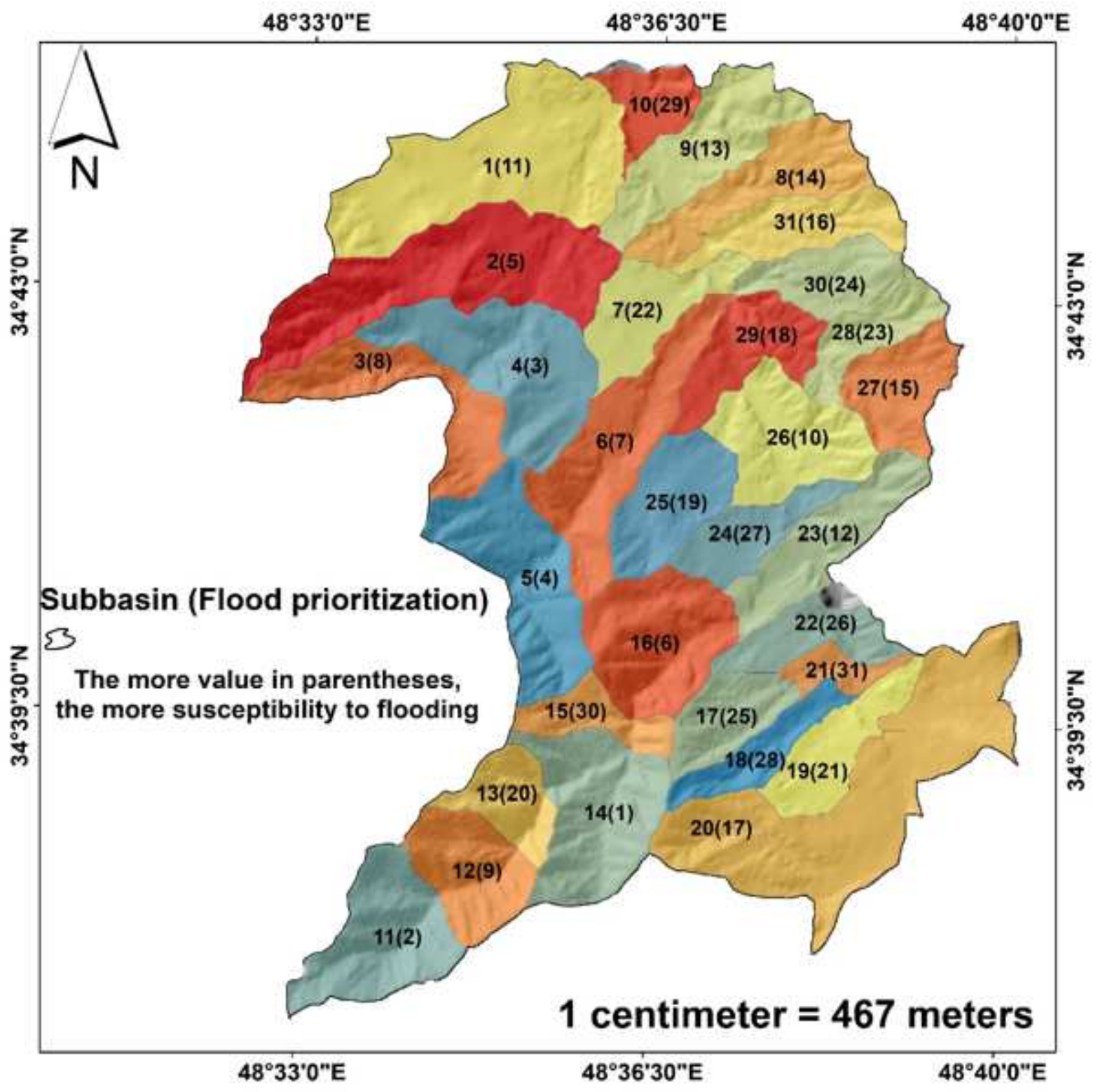

Figure 5

Flood prioritization of the case study Note: The designations employed and the presentation of the material on this map do not imply the expression of any opinion whatsoever on the part of Research Square concerning the legal status of any country, territory, city or area or of its authorities, or concerning the delimitation of its frontiers or boundaries. This map has been provided by the authors. 